\title{
Evaluation of fluid responsiveness during COVID-19 pandemic: what are the remaining choices?
}

\author{
Ahmed Hasanin ${ }^{1} \cdot$ Maha Mostafa ${ }^{1}$ \\ Received: 28 March 2020 / Accepted: 16 May 2020 / Published online: 25 May 2020 \\ (c) Japanese Society of Anesthesiologists 2020
}

\begin{abstract}
Non-protocolized fluid administration in critically ill patients, especially those with acute respiratory distress syndrome (ARDS), is associated with poor outcomes. Therefore, fluid administration in patients with Coronavirus disease (COVID-19) should be properly guided. Choice of an index to guide fluid management during a pandemic with mass patient admissions carries an additional challenge due to the relatively limited resources. An ideal test for assessment of fluid responsiveness during this pandemic should be accurate in ARDS patients, economic, easy to interpret by junior staff, valid in patients in the prone position and performed with minimal contact with the patient to avoid spread of infection. Patients with COVID19 ARDS are divided into two phenotypes ( $\mathrm{L}$ phenotype and $\mathrm{H}$ phenotype) according to their lung compliance. Selection of the proper index for fluid responsiveness varies according to the patient phenotype. Heart-lung interaction methods can be used only in patients with L phenotype ARDS. Real-time measures, such a pulse pressure variation, are more appropriate for use during this pandemic compared to ultrasound-derived measures, because contamination of the ultrasound machine can spread infection. Preload challenge tests are suitable for use in all COVID-19 patients. Passive leg raising test is relatively better than mini-fluid challenge test, because it can be repeated without overloading the patient with fluids. Trendelenburg maneuver is a suitable alternative to the passive leg raising test in patients with prone position. If a cardiac output monitor was not available, the response to the passive leg raising test could be traced by measurement of the pulse pressure or the perfusion index. Preload modifying maneuvers, such as tidal volume challenge, can also be used in COVID-19 patients, especially if the patient was in the gray zone of other dynamic tests. However, the preload modifying maneuvers were not extensively evaluated outside the operating room. Selection of the proper test would vary according to the level of healthcare in the country and the load of admissions which might be overwhelming. Evaluation of the volume status should be comprehensive; therefore, the presence of signs of volume overload such as lower limb edema, lung edema, and severe hypoxemia should be considered beside the usual indices for fluid responsiveness.
\end{abstract}

Keywords Fluid responsiveness $\cdot$ Septic shock $\cdot$ COVID-19 $\cdot$ Pandemic $\cdot$ Heart-lung interaction $\cdot$ Passive leg raising test

\section{Abbreviations}

ARDS Acute respiratory distress syndrome

CO Cardiac output

COVID-19 Coronavirus disease 2019

Ahmed Hasanin

ahmedmohamedhasanin@gmail.com

Maha Mostafa

maha.mostafa@cu.edu.eg

1 Department of Anesthesia and Critical Care Medicine, Faculty of Medicine, Cairo University, 01 Elsarayah Street, Elmanyal, Cairo 11559, Egypt

\section{Background}

The Coronavirus disease 2019 (COVID-19) pandemic is major threat facing the medical care community. While respiratory failure is the most serious complication in patients with COVID-19, a considerable number of patients develop acute circulatory failure [1]. In the largest cohort of patients with COVID-19 pneumonia, the incidence of circulatory shock was $30 \%$ [1].

Fluid administration is essential in patients with shock; however, excessive fluid administration in critically ill patients is associated with poor outcomes. Patients with acute respiratory distress syndrome (ARDS) are more likely to be harmed from unnecessary fluid administration. It is generally recommended to maintain a restrictive fluid 
strategy in patients with ARDS including patients with COVID-19 [2]. Therefore, careful evaluation of the volume status is essential in these patients.

The commonest type of shock in these patients is distributive shock; however, many reports had shown the presence of cardiac injury which reached an incidence of $12 \%$ in patients with COVID-19 pneumonia [3], and 23\% among critically ill patients with COVID-19. Furthermore, a history of cardiac morbidity was reported in $40 \%$ of patients who developed COVID-19 pneumonia [4]. This high prevalence of cardiac injury and/or history of cardiac morbidity among patients with COVID-19 pneumonia increases the need for meticulous fluid management to avoid circulatory overload.

Fluid responsiveness is defined as the ability of the patient to increase the cardiac output $(\mathrm{CO})$ in response to fluid administration. The aim of evaluation of fluid responsiveness is to discriminate patients who will benefit from fluid administration, so that to avoid unnecessary administration of fluids in non-responders [5].

This short review aims to provide a summarized overview for current challenges for evaluation of fluid responsiveness during COVID-19 pandemic, the available tests for fluid responsiveness, the pros and cons for the commonly used tests, and the recommendations for the most appropriate parameters in these patients.

\section{What are the current challenges with fluid responsiveness during COVID-19 pandemic?}

\section{The increased role of fluid responsiveness in the latest guidelines}

Until recently, an initial crystalloid bolus of $30 \mathrm{~mL} / \mathrm{kg}$ was strongly recommended during resuscitation of patients with septic shock. This recommendation has been recently criticized in favor of individualized approach for fluid management [6]. The latest sepsis guidelines which were released during the COVID-19 pandemic had removed the $30 \mathrm{~mL} / \mathrm{kg}$ bolus-recommendation and provided more attention towards the use of dynamic methods for evaluation of fluid responsiveness [2]. This change in recommendations increases the interest towards fluid responsiveness evaluation as the main method for guiding fluid administration in patients with COVID-19, especially when a conservative approach is the recommended fluid protocol during their management [2].

\section{The impact of limited resources}

The use of fluid responsiveness indices during a pandemic requires a special approach towards a balance between the accuracy of the test and its applicability in situations of mass admissions and limited resources. The limited-resource situation during this pandemic is not only due to the lack of equipment nor, medical disposables, but also due to the lack of physician experience with the use of sophisticated monitors. Although the limited-resource situation usually depends on the level of healthcare in the country which is usually related to its income, we believe that a pandemic can produce a limited-resource situation even in developed, high-income countries if the number of admissions exceeded the capacity of their healthcare system [7, 8].

Evaluation of different tests from the economic point of view differs according to the level of healthcare in the country. For example, in low-income countries, it is rarely to find a real-time $\mathrm{CO}$ monitor, because most of these monitors require expensive disposables. The most available tool for measurement of the $\mathrm{CO}$ in these settings is ultrasound. Ultrasound is considered relatively economic, because one machine can serve many patients without the need for expensive disposables; however, the use of ultrasound in COVID19 pandemic might spread infection through contamination of the machine and/or the close contact between the physician and the patient.

The second aspect in the evaluation of different indices in low-resource settings is the feasibility of using with junior staff. The shortage in intensivists was reported during the pandemic $[7,8]$. This shortage was more significant in senior staff. Therefore, the use of ultrasound for measurement of the $\mathrm{CO}$, for example, might not be feasible, because it requires reasonable operator experience; thus, the use of surrogates such as pule pressure would be more practical.

\section{The disease phenotype}

The progress of hypoxemia through the course of COVID-19 is divided into two stages. In the early stage of the disease, disruption of pulmonary perfusion increases the vascular permeability and results in lung edema which is represented radiologically by ground glass appearance. In this stage, which is termed as L phenotype, there is a low elastance, near normal lung compliance; therefore, the patient can be ventilated at a tidal volume of $8 \mathrm{~mL} / \mathrm{kg}$ (i.e., no need for extremely low tidal volume) [9]. With the disease progress, an advanced stage develops, characterized by neutrophil infiltration, marked edema, and development of lung atelectasis. This late stage of the disease, termed $\mathrm{H}$ phenotype, differs from the early stage in the presence of high elastance and low compliance; therefore, patients with the later phenotype are usually ventilated at high positive end-expiratory pressure and low tidal volumes [9]. As most of the fluid responsiveness tests are influenced by the tidal volume and the positive end-expiratory pressure, discrimination of the patient phenotype is necessary during evaluation for fluid responsiveness. 


\section{Right-ventricular failure}

Acute Cor Pulmonale is present in $20-25 \%$ of patients with ARDS [10] and has a major role in hemodynamic instability in these patients [11]. In patients with COVID19, right-ventricular failure has two mechanisms: (1) microvascular obstructive thrombo-inflammatory syndrome which results in pulmonary hypertension [12]; (2) the impact of mechanical ventilation on the right-ventricular function [10]. The presence of acute Cor Pulmonale would greatly impact the values of fluid responsiveness tests, especially heart-lung interaction methods; therefore, it should be carefully excluded before evaluation of fluid responsiveness.

\section{Factors which determine the best parameter for evaluation of fluid responsiveness during COVID-19 pandemic}

These factors include: (1) accuracy of the test in ARDS patient; (2) cost of the test; (3) simplicity for use by physician with limited experience; (4) validity of the test in the prone position which is commonly performed in these patients; (5) ability to perform the test with minimal contact with the patients to avoid infection.

\section{Tests for evaluation of fluid responsiveness in COVID-19}

Four main groups for evaluation of fluid responsiveness are available; all of them depend on the application of fluid challenge after which the patient's response is evaluated. These four groups are: (1) real-time heart-lung interaction methods; (2) ultrasound-derived heart-lung interaction methods; (3) preload challenge techniques; (4) preload modifying maneuvers.

\section{Real-time heart-lung interaction methods}

\section{Overview}

These methods rely on the natural, cyclic changes in stroke volume during the respiratory cycle. Several measures are used under this concept such as pulse pressure variation, stroke volume variation, and plethysmography variability index [5].

\section{Suitability during COVID-19 pandemic?}

According to the classification of COVID-19 ARDS, realtime heart-lung interaction methods can only be used in L phenotype, because patients with this phenotype are ventilated at a tidal volume of $8 \mathrm{~mL} / \mathrm{kg}$. Whilst, patients with $\mathrm{H}$ phenotype are characterized by reduced lung compliance and are usually ventilated at low tidal volumes; both conditions are limitations with the heart-lung interaction methods [13]. Heart-lung interaction methods are less accurate in the prone position [14]. The presence of right-ventricular failure is another limitation which should be excluded before interpretation of heart-lung interaction methods [10]. Some of these measures, such as pulse pressure variation, are also limited by the need to invasive arterial line and special connections which might be deficient in situations of overwhelming number of critical patients (Table 1).

\section{Ultrasound-derived heart-lung interaction methods}

\section{Overview}

These methods depend on the cyclic, respiratory-induced changes in the diameter of great veins or the blood flow in large arteries. The commonest vein whom respiratory variations are used for this purpose is the Inferior Vena Cava. Other ultrasound-derived methods include Internal Jugular Vein respiratory variations, aortic velocity, and carotid artery velocity variations [5].

Table 1 Evaluation of heart-lung interaction methods in detecting fluid responsiveness

\begin{tabular}{lllll}
\hline & Accurate in ARDS & Economic & $\begin{array}{l}\text { Can be interpreted by un- } \\
\text { experienced physician } \\
\text { spread infec- } \\
\text { tion }\end{array}$ \\
\hline Pulse pressure variation & No & No (needs expensive disposables) & Yes & Low \\
Stroke volume variation & No & No (needs expensive disposables) & Yes & Low \\
Plethysmography variability index & No & Yes & Yes & Low \\
Ultrasound-derived measures & In-sufficient data & Yes (needs ultrasound machine only) & No & High \\
\hline
\end{tabular}

$A R D S$ acute respiratory distress syndrome 


\section{Suitability during COVID-19 pandemic?}

Ultrasound-derived methods are non-invasive and relatively economic; however, the use of ultrasound in such a highly infectious disease might transmit infection through the contaminated machine. Furthermore, the close contact between the physician and the patient might expose the physician to infection. Therefore, we believe that the use of ultrasound should be with great caution and better avoided, if possible, during COVID-19 pandemic (Table 1).

\section{Preload challenge methods}

\section{Overview}

Preload challenge methods are very widely used methods for detecting fluid responsiveness. The most common methods among this category are passive leg raising test, mini-fluid challenge test, and end-expiratory occlusion test.

\section{Suitability during COVID-19 pandemic?}

Preload challenge tests have many advantages over other categories of fluid responsiveness indices such as the validity in non-paralyzed patients and the accuracy in patients with low lung compliance and right-ventricular failure. These advantages make these tests superior to the heart-lung interaction methods in patients with COVID-19. The mini-fluid challenge test carries, when repeated, the risk of fluid overload. Furthermore, mini-fluid challenge induces a 5\% change in the cardiac output; this small change requires a precise $\mathrm{CO}$ monitor which might not be widely available during the pandemic $[15,16]$. Therefore, we suggest that the passive leg raising test is more appropriate in patients with COVID-19.
In the prone position, passive leg raising is not possible; furthermore, most of the available methods (namely the pulse pressure variation, the end-expiratory occlusion test, and the tidal volume challenge test) were proven inaccurate [17]. Trendelenburg maneuver is a good substitute to the passive leg raising test if the patient was in prone position (cut-off value $8 \%$ increase in the cardiac index) [17]. Trendelenburg maneuver is nearly the only measure for fluid responsiveness which showed good accuracy in patients with ARDS in the prone position.

The most important limitation among the preload challenge tests is the need for a real-time $\mathrm{CO}$ monitor [5] which might not be available in resource-limited settings (due to lack of equipment or physician experience). Nevertheless, more simple some surrogates for $\mathrm{CO}$ were introduced such as:

1. Pulse pressure (cut-off value $10 \%$ increase in the pulse pressure after passive leg raising) [18, 19]. Monitoring of the pulse pressure is surely less accurate than monitoring of $\mathrm{CO}$; however, the pulse pressure is easily measured under any circumstances and by any personnel. Pulse pressure is more accurate in ruling-out rather than ruling-in fluid responsiveness.

2. Oximetry-derived perfusion index (cut-off value $9 \%$ increase in the perfusion index after passive leg raising test) [20]. The perfusion index had many advantages such as being a real-time, simple, non-invasive measure which does not require expensive disposables nor sophisticated devices [21].

3. Capillary refill time (cut-off value $27 \%$ decrease in the capillary refill time after passive leg raising test) [22] (Table 2).

Table 2 Evaluation of preload challenge tests and preload modifying maneuvers

\begin{tabular}{lllll}
\hline & Accurate in ARDS & Economic & $\begin{array}{l}\text { Can be interpreted by } \\
\text { un-experienced physi- } \\
\text { cian }\end{array}$ & Likelihood to spread infection \\
\hline $\begin{array}{l}\text { Preload challenge test + CO monitor- } \\
\text { ing }\end{array}$ & Yes & No (needs CO monitor) & Yes & Low (unless ultrasound was used) \\
$\begin{array}{l}\text { Preload challenge test + perfusion } \\
\text { index monitoring }\end{array}$ & Yes & Yes & Yes & Low \\
$\begin{array}{l}\text { Preload challenge test + pulse pres- } \\
\text { sure monitoring }\end{array}$ & Moderate & Yes & Yes & Low \\
$\begin{array}{l}\text { End-expiratory occlusion test } \\
\begin{array}{l}\text { Preload modifying maneuvers + CO } \\
\text { monitoring }\end{array}\end{array}$ & Yes & No (needs CO monitor) & Yes & Low (unless ultrasound was used) \\
$\begin{array}{l}\text { Preload modifying maneuvers + per- } \\
\text { fusion index monitoring }\end{array}$ & Yes & No (needs CO monitor) & Yes & Low \\
\hline
\end{tabular}

ARDS acute respiratory distress syndrome, $C O$ cardiac output, preload challenge tests passive leg raising test or mini-fluid challenge test, preload modifying maneuvers lung recruitment, sigh maneuver, tidal volume challenge test 


\section{Preload modifying maneuvers}

\section{Overview}

These are relatively recent maneuvers which are performed by inducing a decrease in the stroke volume by increasing the airway pressure [15]. The lower the stroke volume after the maneuver, the more the likelihood to be fluid responder. Preload modifying maneuvers include tidal volume challenge test [23, 24], lung recruitment maneuvers [25, 26], and sigh maneuvers [27].

\section{Suitability during COVID-19 pandemic?}

Many advantages favor the use of preload modifying maneuvers in patients with COVID-19 pneumonia such as the accuracy, the absence of fluid overload, the ability to perform in the gray zone [23], and the validity during low tidal volume ventilation [24]. However, till now, most of the studies which evaluated these maneuvers were performed in the operating room; thus, extrapolation of their results and cut-off values in critically ill patients with low lung compliance should be performed with caution. The tidal volume challenge test can be used in the patients with $\mathrm{L}$ phenotype and not the $\mathrm{H}$ phenotype, because it is not suitable in extremely low lung compliance.

The second limitation of these maneuvers is the need to monitor either the $\mathrm{CO}$ (which needs equipment and/or experience) or the pulse pressure variation (which needs arterial line and special software). However, De Courson et al. [26] used the perfusion index as a surrogate for stroke volume during lung recruitment maneuver (cut-off value $26 \%$ decrease in the perfusion index after lung recruitment) (Table 2).

A full explanation for the steps of performance of the most relevant tests is provided in Table 3. A detailed stepwise approach for evaluation of fluid responsiveness in COVID-19 pandemic is presented in Fig. 1.

\section{Summary and conclusions}

Fluid administration in patients with COVID-19 pneumonia should be properly guided. The choice of an index to guide fluid management during a pandemic with mass patient admissions is challenging. The key factors for choice of a test are the accuracy in patients with ARDS, the cost, the feasibility for application by junior staff, the validity in patients in the prone position, and the compliance with infection control regulations.

Heart-lung interaction methods can be used in patients with L phenotype COVID-19 ARDS. Real-time measures, such a pulse pressure variation, are more appropriate for use 


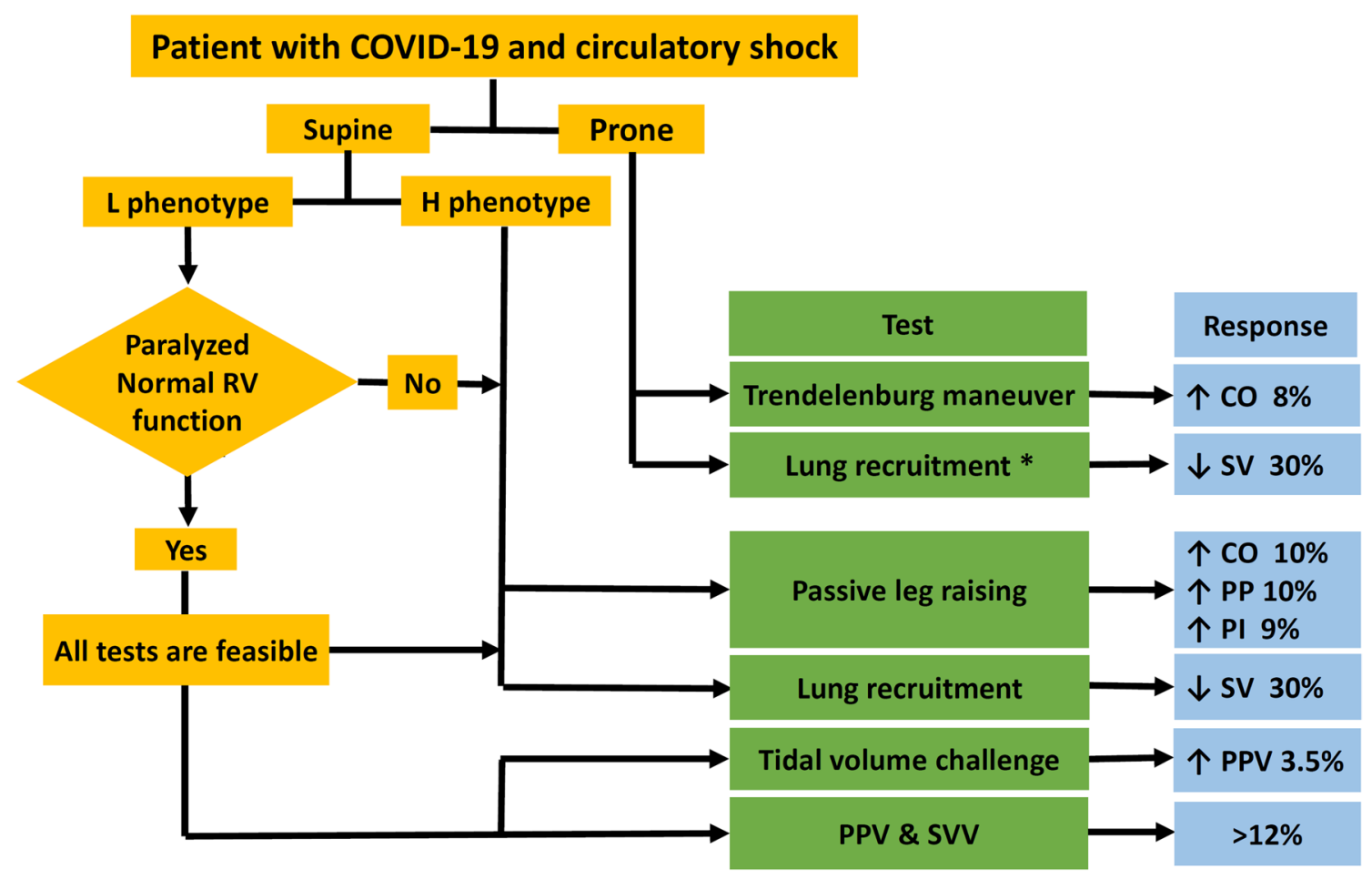

Fig. 1 Summarized approach for evaluation of fluid responsiveness in patients with COVID-19 and circulatory shock. $C O$ cardiac output, COVID-19 Coronavirus disease 2019, PI perfusion index, PP

during the pandemic compared to ultrasound-derived measures, because contamination of the ultrasound machine can spread infection. The use of real-time heart-lung interaction measures requires a paralyzed patient with normal right-ventricular function. Preload challenge tests are suitable for use in all patients. The passive leg raising test is relatively better than the mini-fluid challenge test, because it can be repeated without overloading the patient with fluids. Trendelenburg maneuver is a suitable alternative to the passive leg raising test in patients with prone position. The use of preload challenge tests is limited by the need to real-time $\mathrm{CO}$ monitor. If $\mathrm{CO}$ measurement was not possible, the response to the passive leg raising test could be traced by measurement of the pulse pressure, the perfusion index, or the capillary refill time. Preload modifying maneuvers, such as tidal volume challenge, can also be used in COVID-19 patients, especially if the patient was in the gray zone of other dynamic tests. However, the preload modifying maneuvers were not extensively evaluated outside the operating room. Selection of the proper test would vary according to the level of healthcare in the country and the load of admissions which might be overwhelming. Evaluation of the volume status should be comprehensive; therefore, the presence of signs of volume overload such as lower limb edema, lung edema, and severe hypoxemia should be considered beside the usual indices for fluid responsiveness. pulse pressure, $P P V$ pulse pressure variation, $R V$ right ventricular, $S V$ stroke volume, $S V V$ stroke volume variation. *Lung recruitment maneuver was not previously investigated in the prone position

Acknowledgements We thank Dr. Menna Alshaarawy, Demonstrator of Anesthesia and Critical Care Medicine for her great help in language edition.

Author contributions AH: was responsible for conception of the idea and drafting of the first manuscript. MM contributed in writing the manuscript and revising the final form.

Funding No funding.

\section{Compliance with ethical standards:}

Conflict of interest The authors declare that they have no competing interests.

\section{References}

1. Wang D, Hu B, Hu C, Zhu F, Liu X, Zhang J, Wang B, Xiang $\mathrm{H}$, Cheng Z, Xiong Y, Zhao Y, Li Y, Wang X, Peng Z. Clinical characteristics of 138 hospitalized patients with 2019 novel coronavirus-infected pneumonia in Wuhan, China. JAMA. 2020;323:1061-9. https://www.ncbi.nlm.nih.gov/pubmed/32031 570.

2. Alhazzani W, Møller MH, Arabi YM, Loeb M, Gong MN, Fan E, Oczkowski S, Levy MM, Derde L, Dzierba A, Du B, Aboodi M, Wunsch H, Cecconi M, Koh Y, Chertow DS, Maitland K, Alshamsi F, Belley-Cote E, Greco M, Laundy M, Morgan JS, Kesecioglu J, McGeer A, Mermel L, Mammen MJ, Alexander PE, Arrington A, Centofanti JE, Citerio G, Baw B, Memish ZA, 
Hammond N, Hayden FG, Evans L, Rhodes A. Surviving Sepsis Campaign: guidelines on the management of critically ill adults with Coronavirus Disease 2019 (COVID-19). Intensive Care Med. 2020;46:854-87.

3. Huang C, Wang Y, Li X, Ren L, Zhao J, Hu Y, Zhang L, Fan G, Xu J, Gu X, Cheng Z, Yu T, Xia J, Wei Y, Wu W, Xie X, Yin W, Li H, Liu M, Xiao Y, Gao H, Guo L, Xie J, Wang G, Jiang R, Gao Z, Jin Q, Wang J, Cao B. Clinical features of patients infected with 2019 novel coronavirus in Wuhan, China. Lancet. 2020;395:497-506.

4. Chen N, Zhou M, Dong X, Qu J, Gong F, Han Y, Qiu Y, Wang J, Liu Y, Wei Y, Xia J, Yu T, Zhang X, Zhang L. Epidemiological and clinical characteristics of 99 cases of 2019 novel coronavirus pneumonia in Wuhan, China: a descriptive study. Lancet [Internet]. 2020;395:507-13. https://doi.org/10.1016/S0140 $-6736(20) 30211-7$.

5. Hasanin A. Fluid responsiveness in acute circulatory failure. $\mathbf{J}$ intensive care [Internet]. 2015;3:50. https://www.jintensivecare. com/content/3/1/50 (cited 1 Dec 2015).

6. Marik PE, Byrne L, van Haren F. Fluid resuscitation in sepsis: the great $30 \mathrm{~mL}$ per kg hoax. J Thorac Dis [Internet]. 2020;12:S3747. https://jtd.amegroups.com/article/view/34911/html.

7. Ji Y, Ma Z, Peppelenbosch MP, Pan Q. Potential association between COVID-19 mortality and health-care resource availability. Lancet Glob Health [Internet]. 2020;8:e480. https://doi. org/10.1016/S2214-109X(20)30068-1.

8. Xie J, Tong Z, Guan X, Du B, Qiu H, Slutsky AS. Critical care crisis and some recommendations during the COVID-19 epidemic in China. Intensive Care Med [Internet]. 2020;46:837-40. https:// doi.org/10.1007/s00134-020-05979-7.

9. Gattinoni L, Chiumello D, Caironi P, Busana M, Romitti F, Brazzi L, Camporota L. COVID-19 pneumonia: different respiratory treatment for different phenotypes? Intensive Care Med. 2020. https://doi.org/10.1007/s00134-020-06033-2.

10. Vieillard-Baron A, Matthay M, Teboul JL, Bein T, Schultz M, Magder S, Marini JJ. Experts' opinion on management of hemodynamics in ARDS patients: focus on the effects of mechanical ventilation. Intensive Care Med. 2016;42:739-49.

11. Paternot A, Repessé X, Vieillard-Baron A. Rationale and description of right ventricle-protective ventilation in ARDS. Respir Care. 2016;61:1391-6.

12. Ciceri F, Beretta L, Scandroglio AM, Colombo S, Landoni G, Ruggeri A, Peccatori J, D’Angelo A, De Cobelli F, RovereQuerini P, Tresoldi M, Dagna L, Zangrillo A. Microvascular COVID-19 lung vessels obstructive thromboinflammatory syndrome (MicroCLOTS): an atypical acute respiratory distress syndrome working hypothesis. Crit Care Resusc. 2020.

13. Teboul JL, Monnet X. Pulse pressure variation and ARDS. Minerva Anestesiol. 2013;79:398-407.

14. Messina A, Montagnini C, Cammarota G, Giuliani F, Muratore L, Baggiani M, Bennett V, Della Corte F, Navalesi P, Cecconi M. Assessment of fluid responsiveness in prone neurosurgical patients undergoing protective ventilation: role of dynamic indices, Tidal volume challenge, and end-expiratory occlusion test. Anesth Analg [Internet]. 2020;130:752-61. https://doi. org/10.1213/ANE.0000000000004494.

15. Messina A, Dell'Anna A, Baggiani M, Torrini F, Maresca GM, Bennett V, Saderi L, Sotgiu G, Antonelli M, Cecconi M. Functional hemodynamic tests: a systematic review and a metanalysis on the reliability of the end-expiratory occlusion test and of the mini-fluid challenge in predicting fluid responsiveness. Crit Care [Internet]. 2019;23:264. https://www.ncbi.nlm.nih.gov/ pubmed/28774325
16. Shi R, Monnet X, Teboul J. Parameters of fluid responsiveness. Curr Opin Crit Care. 2020;26:319-26.

17. Yonis H, Bitker L, Aublanc M, Ragey SP, Riad Z, Lissonde F, Louf-Durier A, Debord S, Gobert F, Tapponnier R, Guérin $\mathrm{C}$, Richard J-C. Change in cardiac output during Trendelenburg maneuver is a reliable predictor of fluid responsiveness in patients with acute respiratory distress syndrome in the prone position under protective ventilation. Crit Care [Internet]. 2017;21:295. https://www.ncbi.nlm.nih.gov/pubmed/29208025.

18. Ait-Hamou Z, Teboul J-L, Anguel N, Monnet X. How to detect a positive response to a fluid bolus when cardiac output is not measured? Ann Intensive Care [Internet]. 2019;9:138. https:// www.ncbi.nlm.nih.gov/pubmed/31845003.

19. Monnet X, Marik P, Teboul J-L. Passive leg raising for predicting fluid responsiveness: a systematic review and meta-analysis. Intensive Care Med. 2016;42:1935-47.

20. Beurton A, Teboul J-L, Gavelli F, Gonzalez FA, Girotto V, Galarza L, Anguel N, Richard C, Monnet X. The effects of passive leg raising may be detected by the plethysmographic oxygen saturation signal in critically ill patients. Crit Care [Internet]. 2019;23:19. https://doi.org/10.1186/s13054-019-2306-z.

21. Hasanin A, Mukhtar A, Nassar H. Perfusion indices revisited. J Intensive Care [Internet]. 2017;5:24. https://doi.org/10.1186/ s40560-017-0220-5.

22. Jacquet-Lagrèze $M$, Bouhamri N, Portran P, Schweizer R, Baudin F, Lilot M, Fornier W, Fellahi J-L. Capillary refill time variation induced by passive leg raising predicts capillary refill time response to volume expansion. Crit Care [Internet]. 2019;23:281. https://doi.org/10.1186/s13054-019-2560-0.

23. Min JJ, Gil NS, Lee JH, Ryu DK, Kim CS, Lee SM. Predictor of fluid responsiveness in the "grey zone": augmented pulse pressure variation through a temporary increase in tidal volume. Br J Anaesth [Internet]. 2017;119:50-6. https://doi.org/10.1093/bja/ aex074.

24. Myatra SN, Prabu NR, Divatia JV, Monnet X, Kulkarni AP, Teboul JL. The changes in pulse pressure variation or stroke volume variation after a "tidal volume challenge" reliably predict fluid responsiveness during low tidal volume ventilation. Crit Care Med. 2017;45:415-21.

25. Biais M, Lanchon R, Sesay M, Le Gall L, Pereira B, Futier E, Nouette-Gaulain K. Changes in stroke volume induced by lung recruitment maneuver predict fluid responsiveness in mechanically ventilated patients in the operating room. Anesthesiology. 2017;126:260-7.

26. de Courson H, Michard F, Chavignier C, Verchère E, NouetteGaulain K, Biais M. Do changes in perfusion index reflect changes in stroke volume during preload-modifying manoeuvres? J Clin Monit Comput [Internet]. 2019. https://www.ncbi.nlm.nih.gov/ pubmed/31853812.

27. Messina A, Colombo D, Barra FL, Cammarota G, De Mattei G, Longhini F, Romagnoli S, DellaCorte F, De Backer D, Cecconi M, Navalesi P. Sigh maneuver to enhance assessment of fluid responsiveness during pressure support ventilation. Crit Care [Internet]. 2019;23:31. https://doi.org/10.1186/s13054-018-2294-4.

Publisher's Note Springer Nature remains neutral with regard to jurisdictional claims in published maps and institutional affiliations. 